\title{
Source Study on Modeling of Pour Pot and Tin Pot Made in China's Shouzhou Kiln
}

\author{
Xiaochen Geng \\ Postdoctoral Research Station \\ Nanjing Normal University \\ Nanjing, Jiangsu, China \\ Institute of Arts and Crafts \\ Fuzhou University \\ Xiamen, Fujian, China
}

\begin{abstract}
This paper analyzes the shape forming reasons of pour pot made in China's Shouzhou kiln, summarizes the artistic shaping features of pour pot made in Shouzhou kiln and explores the influence of shape of pour pot made in China's Shouzhou kiln on tin pots of Song Dynasty, hoping to explore the influence of the artistic features of creation in the Tang Dynasty on the creation in the Song Dynasty.
\end{abstract}

Keywords—Shouzhou kiln; pour pot; tin pot; source

\section{INTRODUCTION}

Shouzhou kiln is located in Huainan City, Anhui, China and it is one of the famous pottery firing kiln sites of China's Tang Dynasty. During the long development process, it creates diversified categories and abundant shape styles and its ceramic shape gets gradually popularized in people's daily life. With a century's inheritance and on the basis of craft and modeling of Sui Dynasty, Shouzhou kiln starts making innovations in shape style and glazing color and firing yellow glazed porcelain, entering a golden period of great prosperity. Every new artistic modeling needs a process starting from sprouting to development and maturity. The process has its own law, the key of which lies in grasp and connection of different things' different features. Only by doing so, can their respective features be followed and can innovations be made according to the varying pattern of artistic characteristics. It is also true for the mutual relation between the shape of pour pot and tin spot shape. Innovation and change in shape is of prime importance. In the currently discovered Shouzhou kiln, there is a large amount of various pots made in accordance with tea culture and spirits culture. Such kind of pots survive in great quantities and there are also many archaeological excavations. This paper chooses the representative pour pot to analyze its shape style and explore Shouzhou kiln's shape style developing evolution law in order to have an insight on the source of influence of creations' shape and structure in Song Dynasty on

2015 China Postdoctoral Science Foundation Artistic Theory Project. Project No.: 2015M570465, phased achievement

2014 China National Social Science Fund Artistic Theory Youth Project. Project No.: 2014CG03413, approval No.: 14CG134, phased achievement

High-level "211" Engineering University Construction Project, Fuzhou University Artistic Theory and Theoretical Subject Support Program, phased achievement. artistic characteristics of creations in China's Tang Dynasty.

\section{Shaping ReASONS OF Pour Pot MAdE In Shouzhou KILN}

In its long development process, China's Shouzhou kiln creates abundant categories and shape style. Its spout modeling doesn't appear until the early phase of Tang Dynasty and it gets popular in the middle of Tang Dynasty. Basic features of spout modeling at the early stage are short-stream, brevicollis and bulging belly "Fig.1". "Pot at the earliest is round. Bronze ware comes after the earthenware. Round pot's service time is the longest, thus it becomes the general name." ${ }^{1}$ The pot at the earliest has no handle, liu or other accessories, similar to bottles in modeling. In the Neolithic Age when primitive men start living a settled life, pots and bottles in various shapes are created for the convenience of life. Pots and bottles at that time usually have a large volume and their basic features are deep bellies and convergence mouths with a tether. They are mainly used to hold wine syrup or grain. ${ }^{2}$ Before Tang Dynasty, pots mostly exist in the shape of bottle. Because of constant changes in people's life style, life content and various cultural elements, including tea and alcohol drinking and fetes, part of the shape needs adjustments to adapt to those changes and therefore new shapes come into being. Before Tang Dynasty, pots and bottles are mainly used to keep mild wine in storage. Due to development of brewing technique in Tang Dynasty, cru increases to a large extent. Therefore, large spots are no longer suitable for alcohol drinking and spout modeling slashes its volume with an extra handle and liu for the convenience of holding and alcohol injection. "Pointing-tea" technique appears in the later period of Tang Dynasty, namely first boil the water in the tea pot and put tea dust in a bowl in advance, then pour the boiled water into the bowl. Since most tea pots are made of ceram and metal, they feel extremely hot after boiling. It will be very inconvenient for holding if there is no handle and liu. Therefore, pots with a spout used for boiling tea or water usually have a beam or a horizontal handle in order to prevent the hot pot from hurting the hand. ${ }^{3}$ From later period of Western Han Dynasty to Tang Dynasty, various types of life style coexist. ${ }^{4}$ From the Han Xizai Night Banquet of Southern Tang Dynasty, we can see that high seating devices and pillow beds have appeared at that time. After 
generation of high seating devices, their placement location gets higher correspondingly. Due to changes in usage and residence life style, tether and ear of pots gradually lose their original functions and get changed. Functionally, liu is the part of pot from which liquid is poured out and it has an excellent guiding function. Handle on the pot makes it convenient for holding and alcohol injection. The liu on one side of the pot determines alcohol's flow direction and makes direct injection of alcohol into the cup available. Tether and ear also evolve into liu, improving the pot's function of pouring out water. Utensils of pour pot type come into being in order to meet the actual need of production and life. Satisfaction of practicability becomes an inherent regularity of all creation activities and it is also the internal reason driving constant reform and development of product modeling. Due to complex accessory modeling of pot, utensils called "pot" are different in modeling. In China's creation development history, modeling forms of pour pot experience a chapter of thick and heavy colors, which is an important part of modeling design evolution. Therefore, design of "liu" "Fig. 2" is the most outstanding innovation of pour pot modeling created by Shouzhou kiln. Appearance of "liu" brings great changes to modeling forms of pot and prototype of current pot is created in modeling evolution of bottle or pot, significantly influencing modeling design of metal and porcelain products and so on in the following Song Dynasty.

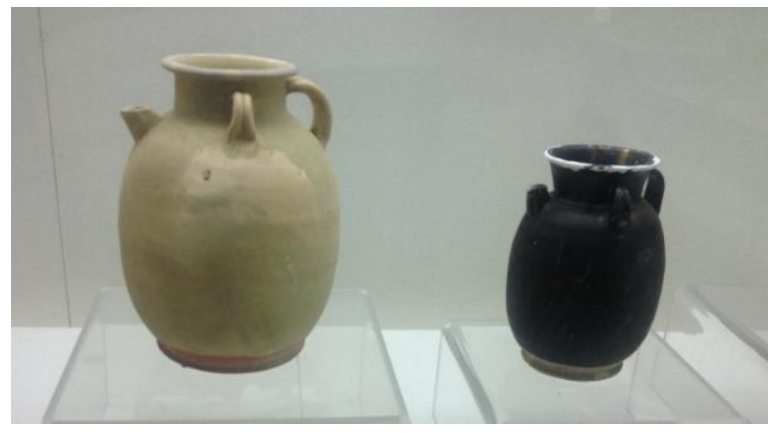

Fig. 1. Pour pot in Huainan Museum

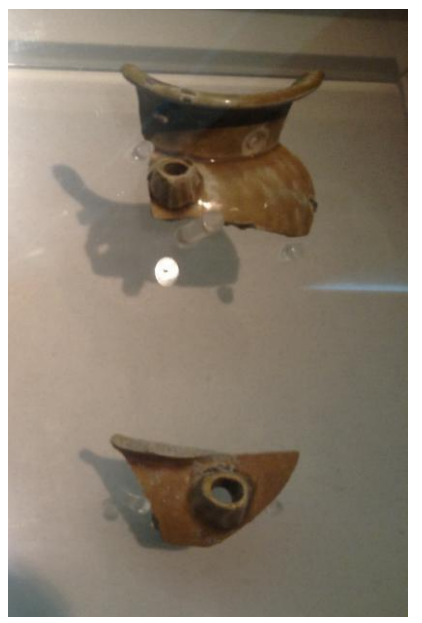

Fig. 2. Shot in Huainan Museum

\section{ARTISTIC CHARACTERISTICS OF TIN POT MODELING OF SONG DYNASTY}

As early as in late Shang Dynasty, tin metal and its products in a pure sense have appeared. Seeing from tin content of the tin bar unearthed in Yin $\mathrm{Xu}$, Henan and tin Ding and tin Gui unearthed in Western Zhou tombs in Baoji, Shaanxi, we can know that in the Shang and Zhou Dynasties, China's independent tin smelting craft has reached a high level. During Qin and Han dynasty, a large part of tin is used to cast coins and tin becomes an important material of coin casting alloy. After Han Dynasty, there are clear regulations on tin usage in Tang Dynasty. In the Tang Records · Food and Goods Record, there is a saying "Imperial edict in the third year of Taihe: Buddha statue should be made from lead, tin, soil and wood." The government controls part of metals, including tin. Tinware is widely used in folk in the Song Dynasty.

In Wu Zimu's Dream Beam Catalog, there is a saying "Previously, there were several famous shops on the market street of Lin'an, like Hu's and Feng's Powder Shop, Wang's Dye Red Rouge Shop, Huai Ling Pouring Tin Shop and so on".6 The record in this book proves that tinware has been widely used in people's daily life in folk at that time. In terms of modeling function, the belly part of tin pot of Song Dynasty can be effectively used, therefore belly is the most important part of tin pot and its design is usually closely associated with utility function. Pot used for holding water usually has a deep belly and a large mouth. Its belly is usually plump with a large caliber and a large bottom diameter, resulting in high utilization ratio. Generally, the belly of wine pot is much smaller than that of tea pot. Wine pot usually has a small caliber and its bottom diameter can be large or small. Therefore, the volume of imaginary space of tin pot's abdominal cavity determines its practical capacity. Some elements seem more important in design of pot utensils, like the location of the belly's maximum abdominal diameter, proportion of belly's volume in the whole size of the pot and belly wall's curve variation. There are active and abundant changes in various types of pots' belly modeling styles of China's Song Dynasty. Round and bulged design is a key part of modeling and it probably derives from the design of fourtether bottle created by Shouzhou kiln at the early phase. Primarily, ampulla is the key to four-tether bottle's round modeling style. Round and bulged ampulla modeling is created on the basis of functional factor, creating plump lines and graceful modeling forms. There are also different types of pots with round and bulged belly modeling. Different types are designed according to different locations of ampulla's maximum abdominal diameter. Basically, there is abdominal curl, round belly and sagging belly. Maximum diameter of abdominal curl is slightly higher, round belly's maximum diameter is in the middle and sagging belly's stays down. Pot with a round fold belly also boasts a round and bulged belly with fold edges. There are also differences in location of fold edges. Some fold edges stay upper, some stay in the middle and some stay down. 


\section{ANALysis on Relation Between Pour Pot MADE IN SHOUZHOU KILN AND TIN POT OF SONG DYNASTY}

\section{A. Tin Pot of Song Dynasty Changes and Develops on the Basis of Inheritance}

For the convenience of handling and holding, lifting beam and handles are added to pour pot utensils made in Shouzhou kiln, having great influence on products of the following dynasties. First, tin pot is widely used in folk in Song Dynasty and the above mentioned tin pot has entered the market. Product modeling evolves gradually. It also becomes a trend to imitate classic pour pot modeling of Tang Dynasty. Seeing from the above analysis on pour pot made in Shouzhou kiln, each part of the pot has diversified modeling methods and different and complex shapes. There are also big differences among the shape of the ware. Thus, it can be said that Shouzhou kiln's pour pot modeling is the midst of constant changes. From the above analysis on tin pot modeling of Song Dynasty, we can know that tin pot's principal part and accessory modeling methods are varying and tin pot's principal part and accessories together form a complex style of tin pot. On the whole, tin pot's modeling design is mainly closely related to utensils' functions of use, material, beautyappreciation and so on. Design also follows the principle of form beauty, pursuing contrast, diversity or unified appearance in order to give people an aesthetic feeling of unification and coordination. The effect of unification and coordination can also be achieved in contrast. There is mutual learning between Shouzhou kiln's pour pot and tin pot design. Their forms and images are very concise. It may be said that multiple modelings are integrated into one, achieving the diversified and luxuriant overall effect. Although the modeling imitates Shouzhou kiln's pour pot of Tang Dynasty, it inherits and changes at the same time. Shouzhou kiln's pour pot of Tang Dynasty has no cover and dust can fall into the pot. On the basis of imitating Shouzhou kiln's modeling, tin pot of Song Dynasty has an extra cover on the mouth, both practical and beautiful. It is a new process among changes of pot utensil's modeling design and it also lays the foundation for high furniture's new pot modeling styles.

\section{B. First Representative of Early Maritime Silk Road In China}

Relying on convenient transportation of Yao River and Huai River basin, Shouzhou kiln becomes the famous ceramic production base at that time. It is well-known and prosperous for a long time. It produces abundant types of porcelain with unique modeling, meeting people's need in daily life and the need of trade culture and promoting regional economic and social development. Most kiln eyes in Shouzhou are located on the two sides of Gaotang Lake and Yao River. Yao River is the waterway hub connecting Gaotang Lake and Huai River "Fig. 3". It not only connects every large kiln factory, but also undertakes transportation of various kinds of materials and products. With the help of Huai River's outward transport advantage, export sales of Shouzhou kiln's porcelain are improved. Ceramic wares produced in ancient Shouzhou are transported here by wooden sailing boat along Yao River and exchanged for salt, farm tools, sundry goods and other things transported here from Yangzhou and other places. These ceramic wares can continue to go through Huai River canal towards the east and north, boosting "development of Huainan and Huaibei areas, Henan, Jiangsu, Hubei and other places".? Earlier on, Shouzhou kiln's ceramic modeling has influenced Henan and other regions. After imitating Shouzhou kiln's pour pot, tin pot of Song Dynasty experiences continuous innovation and makes a figure in maritime silk road's external exchange in the early days. Tinware is found as early as on "South China Sea I ", a sunken ship in the early days of maritime silk road. After identification, it is speculated that this sunken ship may be a trade merchant ship traveling to and fro China, Southeast Asia and Arab countries in Song and Yuan Dynasties " "Fig. 4". It is undoubted that tin pot of Song Dynasty experience continuous innovation on the basis of inheritance and is used for external exchange. Its modeling has gotten substantial development in trade and tin pot modeling is very novel at that time. Inevitably, tin pot products penetrate into society and people's consciousness in commerce and trade activities with and flow of immigrants into Southeast Asia. Therefore, tin pot modeling in early trade also has great influence on Southeast Asia's relevant product modeling.

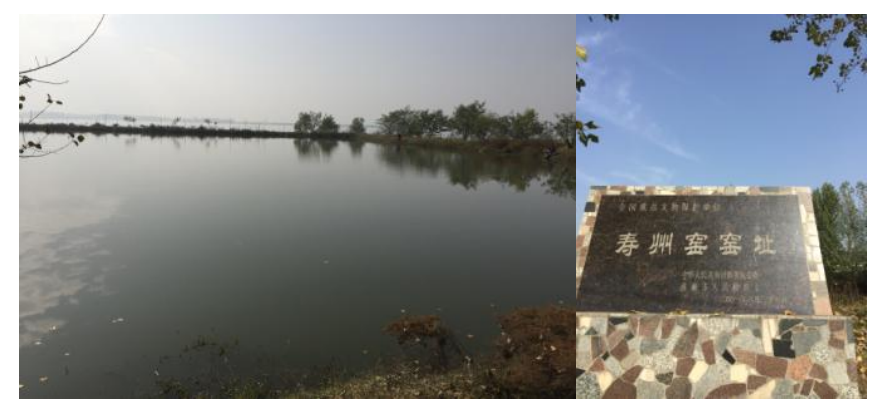

Fig. 3. Shot at the former site of Shouzhou kiln in Huainan and at the Yao River in front of the kiln site

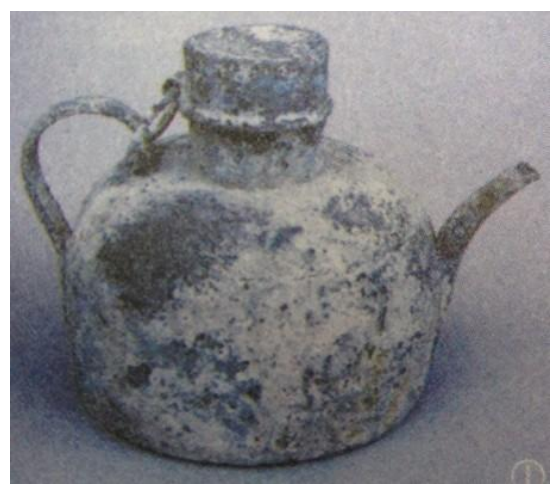

Fig. 4. "South China Sea I " Effluent Tin Pot

Picture Source: Li Qingxin. "South China Sea I " and Maritime Silk Road. China Intercontinental Press, 2010

\section{CONCLUSION}

Modeling features of pour pot made in Shouzhou kiln, China have great influence on modeling of ceramic pot and metal pot in Song Dynasty. Various modeling evolution of various types of pot firstly originates from their function. Tin pot of Song Dynasty has an extra cover on the basis of Shouzhou kiln's pour pot modeling in order to prevent dust from falling into the pot and overflow. Later, for the sake of 
convenience, a chain is added to make pot cover and pot body inseparable. From the above analysis, we can prove that shape style of Shouzhou kiln's pour pot originates from the tether of four-tether pot. The design of liu also lays the modeling foundation for the following pot utensils. Tin pot of Song Dynasty learns from Shouzhou kiln's pour pot modeling in order to satisfy its own operating requirements, based on which various types of modeling styles are created. Therefore, the primary reason why Shouzhou kiln's pour pot modeling develops so well in Song Dynasty is its excellent use function.

\section{REFERENCES}

[1] Huang Shengzhang. Research on Shape Development and Name Change of Pot. Cultural Relics of Central China, Page 26, Issue 2, 1983

[2] Geng Xiaochen. Exploration on Evolution Source of Pot with a Spout Modeling Created by Shouzhou Kiln. Sculpture Magazine, Issue 6, 2016

[3] Jiang Yan. Modeling Development History of Pot Utensils from the Perspective of "Function". Journal of Ceramics, Issue 2, 2007

[4] Zhang Pengchuan. Iconography of Han Xizai Night Banquet. Beijing: Peking University Press, 2014, Page 198

[5] Wu Yugui. Tang Records Compilation and Emendation-Food and Goods Record. Beijing: Zhonghua Book Company Press, 2008

[6] Wu Zimu. Dream Beam Record. Hangzhou: Zhejiang People's Publishing House, 1980, Page 117

[7] Lv Dongliang. Analysis on Forming Reasons of Shouzhou Kiln Series. Heilongjiang History and Annals, Issue 9, 2014

[8] Li Qingxin. "South China Sea I" and Maritime Silk Road. China Intercontinental Press, 2010 